\title{
Reliability of ultrasonography and the Alvarado scoring system in acute appendicitis
}

\author{
Ahmet Sami Yazar ${ }^{1}$, Seher Erdoğan², Ceyhan Şahin ${ }^{3}$, Şirin Güven ${ }^{1}$ \\ Departments of ${ }^{1}$ Pediatrics, ${ }^{2}$ Pediatric Critical Care and ${ }^{3}$ Pediatric Surgery, The University of Health Sciences, Umraniye \\ Research and Training Hospital, Istanbul,Turkey. E-mail:samiyazar@yahoo.com \\ Received: 7th August 2018, Revised: 9th October 2017, 17th December 2017, Accepted: 30th December 2017
}

SUMMARY: Yazar AS, Erdoğan S, Şahin C, Güven Ş. Reliability of ultrasonography and the Alvarado scoring system in acute appendicitis. Turk J Pediatr 2018; 60: 173-179.

In this study, we aimed to evaluate the diagnostic performance of ultrasonography, the Alvarado score, mean platelet volume and C-reactive protein in the diagnosis of acute appendicitis.

Patients admitted to the pediatric emergency department with abdominal pain who were operated on with a preliminary diagnosis of acute appendicitis were evaluated. The patients who had acute appendicitis diagnosis in the histopathological assessment were considered as the Appendicitis (App) Group, while patients who did not have acute appendicitis according to histopathology were considered as the Non-app Group.

Of 200 patients assessed in the study, 137 (68.5\%) were male and $63(31.5 \%)$ were female. Of the patients operated on; 170 (85\%) had acute appendicitis, while the pathological results of $30(15 \%)$ were not consistent with acute appendicitis. The Alvarado score of the patients in App Group was significantly higher than those in Non-app Group $(\mathrm{p}=0.001)$. The sensitivity and specificity of the Alvarado score and ultrasonography were $60 \%, 81.18 \%$ and respectively, for the diagnosis of appendicitis. There were no significant differences ( $p>$ 0.05) in terms of average white blood cell, absolute neutrophil count, platelet count, mean platelet volume and C-reactive protein between the two groups.

According to our study the use of Alvarado Scoring System with ultrasonography is more effective and accurative than ultrasonography performing alone. We recommend performing ultrasonography on patients with right lower quadrant pain and suspected appendicitis admitted to the emergency department and to operate on patients with a ultrasonography-supported appendicitis diagnosis and an Alvarado score of 7 and above. Patients with an appendicitis diagnosis not supported by ultrasonography and an Alvarado score lower than 7 should be closely monitored.

Key words: alvarado score, appendicitis, mean platelet volume, ultrasonography.

Acute appendicitis is one of the most common situations that require emergency surgery. ${ }^{1}$ Not delaying diagnosis is important but negative appendectomy operation rate is also high in most series. The fact that acute appendicitis presents with different complaints can lead to a delay in diagnosis, which also increases the likelihood of perforation. ${ }^{2}$ Negative appendectomy rates are reported to be between $13 \%$ and $34 \%$ in most series. ${ }^{3}$ Diagnostic parameters to reduce the negative appendectomy rate (leukocytes, C-reactive protein, mean platelet volume, interleukin-6, urine 5-hydroxyl indole acetic acid), clinical scoring and imaging techniques in the diagnosis of appendicitis are under investigation. ${ }^{4}$ Ultrasonography (USG) is still the most valuable and non-invasive technique in the diagnosis of acute appendicitis.

Recent studies reported that the pediatric appendicitis score (PAS) is a useful tool

This study was presented as oral presentation at the 5th Cocuk Dostları Cogress, 6-7 May 2017, İstanbul. 
in the evaluation of children with possible appendicitis. ${ }^{5}$ Scores up to 4 help rule out appendicitis, while scores 8 or higher help predict appendicitis. Patients with a PAS of 5-7 may need further radiologic evaluation. ${ }^{6}$ Although using the appendicitis score improves the overall clinical accuracy for diagnosis of appendicitis (from $80 \%$ to $92 \%$ ), the rate of unnecessary appendicectomies is still high (from $8.8 \%$ to $17 \%$ ). ${ }^{7,8}$

In this study, we aimed to investigate the efficacy of ultrasonography, which is noninvasive, easily accessible and has a low cost, the Alvarado score as a clinical scoring system, white blood cell count (WBC), absolute neutrophil count (ANC), mean platelet volume (MPV), and C-reactive protein (CRP) in the diagnosis of real acute appendicitis.

\section{Material and Methods}

This study was performed as a cross-sectional, non-invasive and observational study at the University of Health Sciences, Umraniye Training and Research Hospital between September 2015 and December 2016 at the Pediatric Emergency Department on patients with preliminary acute appendicitis diagnosis that were operated on. The demographic characteristics of the patients (age, gender), clinical signs, white blood cell count (WBC), absolute neutrophil count (ANS), platelet count (PLT), mean platelet volume (MPV), C-reactive protein (CRP) levels, ultrasonography findings, , Alvarado score evaluation, surgical and histopathological results were recorded. The patients who had a diagnosis of acute appendicitis by histopathology were considered as the appendicitis (App) group, while patients without acute appendicitis according to histopathology were considered as Non-app group. Cases with perforation or complicated appendicitis were excluded from the study to rule out the effects on the leucocyte count and fever.

The CRP turbidimetric method (Architect Plus ca 4100, Abbott) was used. Complete blood counts were obtained with an electronic cell counter device (Blood Cell-Dyn 3700 Hematology Analyzer, Abbott).

USG imaging performed routinely to all patients for diagnosis of acute appendicitis.

A Toshiba Aplio-MX (California) ultrasound machine was used for the ultrasonographic evaluation. Cases which had non-compress, a peristaltic, painful sensation, with a wall thickness exceeding $6 \mathrm{~mm}$ containing an appendicolith, with a target mark in the cross-sectional image and dead-end in the longitudinal image, forming inflamed adipose tissue echogenicity where a tubular structure is seen were reported as positive for acute appendicitis. The cases in which appendicitis was not seen or seen as a normal situation were interpreted as negative.

In our study, a clinical scoring system, i.e. the Alvarado score (Table I), was used. The Alvarado score was chosen because it includes the patient's symptoms, findings and laboratory evaluation and has reported accuracy rates between $78 \%$ and $82 \%$ for acute appendicitis. ${ }^{9}$ According to this scoring system, surgery is recommended in patients that have 7 or more points; patients with fewer than 7 points should be monitored. 10

As well as descriptive statistical methods

Table I. Alvarado Score Table.

\begin{tabular}{ll}
\hline Clinical findings & \\
\hline The onset of common pain is localized to right & 1 \\
Loss of appetite & 1 \\
Nausea and vomiting & 2 \\
Sensitivity in the right lower quadrant & 1 \\
Signs of rebound & 1 \\
High fever & 2 \\
Leukocyte increase & 1 \\
Leftward shift in the smear & 10 \\
Total & \\
\hline
\end{tabular}




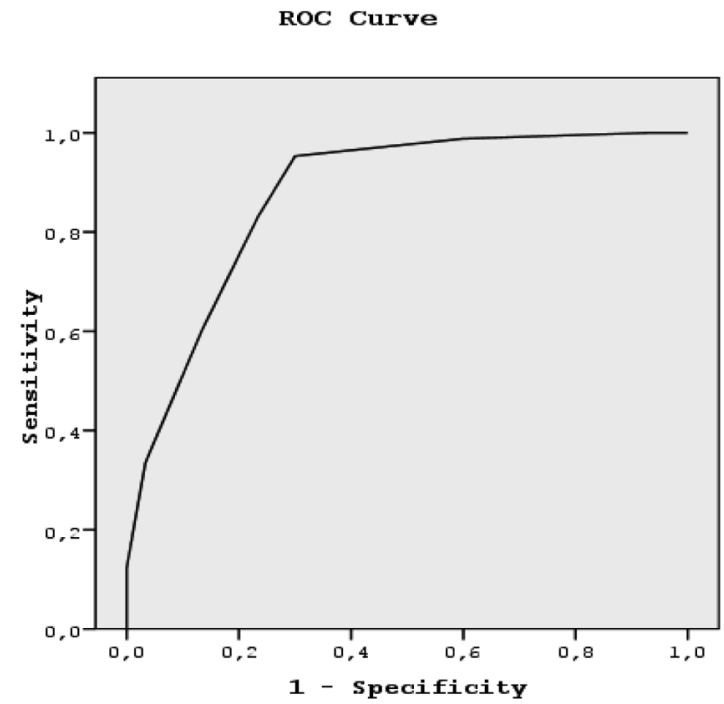

Fig. 1. ROC curve of Alvarado score cut-off 5.

(mean, standard deviation, frequency), for comparisons of parameters showing normal distribution between two groups, Student's t-test was used for comparing quantitative data, while the Mann-Whitney U test was used for the comparison of parameters showing a non-normal distribution. The suitability of normal distribution parameters was evaluated by the Shapiro-Wilk test when assessing the study data.

The optimal cut-off point was selected based on ROC curve analysis. Screening tests were utilized in the sensitivity and specificity calculations. Significance was set at $\mathrm{p}<0.05$. IBM SPSS Statistics 22 (SPSS IBM) was used for the statistical analysis.

The study protocol was approved by the Instituional Ethics Committee of the Umraniye Training and Research Hospital on 08/20/2015 with the report number of 82 . All participation involved informed consent.

\section{Results}

Of 200 patients considered in the study, 137 $(68.5 \%)$ were male and $63(31.5 \%)$ were female. The average age of the patients was $136 \pm 45$ months (41 to 291 months). WBC, ANS, PLT, and MPV values and the Alvarado scores of the patients are shown in Table II.

Of all patients that were operated on; 170 (85\%) had acute appendicitis, while 30 patients (15\%) did not reveal any pathology for acute appendicitis. Five of 30 Non-app had mesenteric lymphadenopathy, and a lymph tumor invading the appendix was detected in one patient. Ultrasonography was positive in 151 patients (75.5\%) and 49 (24.5\%) were negative. The Alvarado score in 106 patients (53\%) was over 8 points, between 5 and 7 in 80 patients $(40 \%)$ and less than 4 in 14 patients (7\%).

When patients in App and Non-app were

Table II. Comparison of Demographic and Clinical Characteristics of the Patients Included in.

\begin{tabular}{|c|c|c|c|}
\hline & $\begin{array}{l}\text { Patients with } \\
\text { histopathologically } \\
\text { proven appendicitis } \\
(\mathrm{n}=170)\end{array}$ & $\begin{array}{l}\text { Patients without } \\
\text { histopathologically } \\
\text { proven appendicitis } \\
(\mathrm{n}=30)\end{array}$ & $\mathrm{p}$ \\
\hline & Mean \pm SD & Mean \pm SD & \\
\hline Female & $50(29.4 \%)$ & $13(43.3 \%)$ & \\
\hline Male & $120(70.6 \%)$ & $17(56.7 \%)$ & $0.194^{*}$ \\
\hline Age (months) & $134 \pm 45$ & $142 \pm 43$ & 0.399 \\
\hline WBC $\left(/ \mathrm{mm}^{3}\right)$ & $15.080 \pm 5.570$ & $13.730 \pm 5.020$ & 0.214 \\
\hline ANC $\left(/ \mathrm{mm}^{3}\right)$ & $12.020 \pm 5.540$ & $10.100 \pm 5.500$ & 0.080 \\
\hline $\operatorname{PLT}\left(/ \mathrm{mm}^{3}\right)$ & $290.420 \pm 78.230$ & $284.0000 \pm 95.38$ & 0.689 \\
\hline MPV (fL) & $7.68 \pm 1$ & $7.64 \pm 1.19$ & 0.830 \\
\hline $\mathrm{CRP}_{(\mathrm{mg} / \mathrm{dl})}$ & $3.83 \pm 5.77$ & $2.77 \pm 3.9$ & $0.396^{* *}$ \\
\hline Alvarado score & $7.8 \pm 1.4$ & $5.2 \pm 1.6$ & 0.001 \\
\hline
\end{tabular}

*Ki-square test; **Mann-Whitney U test; WBC: White blood count; ANC: Absolute neutrophil count; PLT: Platelet; MPV: Mean Platelet volume; CRP: C-Reactive protein; SD: Standard deviation 
Table III. The Sensitivity, Specificity, Positive and Negative Predictive Value, Accuracy Rate of WBC, ANS, USG, and Alvarado Score In Acute Appendicitis Diagnosis.

\begin{tabular}{llllll}
\hline & Sensitivity (\%) & Specificity (\%) & PPV (\%) & NPV( \%) & Accuracy (\%) \\
\hline WBC $\left(\geq 10.000 / \mathrm{mm}^{3}\right)$ & 78.24 & 23.33 & 85.26 & 15.91 & 70.0 \\
ANC $\left(\geq 7.500 / \mathrm{mm}^{3}\right)$ & 77.65 & 33.33 & 86.84 & 20.83 & 71.0 \\
USG & 81.18 & 56.67 & 91.39 & 34.69 & 77.5 \\
Alvarado score $(\geq 5)$ & 98.80 & 40.00 & 90.30 & 85.70 & 58.0 \\
Alvarado score $(\geq 8)$ & 60.00 & 86.67 & 96.23 & 27.66 & 64.0 \\
USG $(+)$ and Alvarado & 85.36 & 90.00 & 96.67 & 24.55 & 87.0 \\
score $(\geq 8)$ & & &
\end{tabular}

PPV: Positive predictive value; NPV: Negative predictive value; WBC: White blood count; ANC: Absolute neutrophil count; USG: Ultrasonography

compared in terms of gender and average age, there was no statistically significant difference $(p>0.05)$. Similarly, there were no significant mean differences $(\mathrm{p}>0.05)$ in terms of average WBC, ANS, PLT, MPV and CRP between the two groups. However, the Alvarado score of the patients in App Group was significantly higher than those in Non-app Grup ( $\mathrm{p}=0.001)$.

USG sensitivity in the diagnosis of acute appendicitis was calculated as $81 \%$ and specifity as $56.6 \%$, with a positive predictive value of $91.3 \%$, a negative predictive value of $34.6 \%$, and an accuracy rate of $77.5 \%$. The sensitivity of an Alvarado score of 8 and over was $60 \%$ and the specifity was $86.6 \%$, with a positive predictive value $96.2 \%$ and a negative predictive value of $27.6 \%$. In patients with positive ultrasonography results, if the Alvarado score was 8 and over, the sensitivity was $51.1 \%$, the specifity was $90 \%$, the positive predictive value was $96.6 \%$ and the negative predictive value was $24.5 \%$ (Table III).

The area under the ROC curve was $87.5 \%$ (Fig $1)$. When the Alvarado score was between 8 , the sensitivity was $60 \%$, the specificity was $86.6 \%$, the positive predictive value was $96.2 \%$ and the negative predictive value was $27.6 \%$.

When the cut-off value for the Alvarado score was 5 the sensitivity of this predictive value was $98.8 \%$, with a specificity of $40 \%$, a positive predictive values of $90.3 \%$ and a negative predictive value of $85.7 \%$.

The average Alvarado score was statistically significantly higher in cases with positive histopathology or USG compared to patients with a negative histopathology or USG result $(p<0.01)$. The Alvarado score was significantly higher in cases with positive USG and histopathology results than in negative cases $(p=0.001)$. The Alvarado scores of patients with $\geq 10,000 / \mathrm{mm}^{3}$ WBC was significantly higher than in patients with $<10,000 / \mathrm{mm}^{3}$ WBC $(p=0.001)$. Similarly, the Alvarado score of patients with ANS $\geq 7500 / \mathrm{mm}^{3}$ was significantly higher when compared to patients with ANS $<7500 / \mathrm{mm}^{3}(\mathrm{p}=0.001)$. There was no statistically significant difference in terms of the Alvarado score between patients with 27.4 MPV and those with $<7.4$ MPV ( $p=$ 0.416), as shown in Table IV.

\section{Discussion}

Although appendicitis is a common disease that requires emergency surgery, a timely and correct diagnosis can be difficult at times. ${ }^{11}$ Non-specific symptoms such as abdominal pain, nausea, vomiting, right lower quadrant tenderness and leukocytosis are usually seen in patients with acute appendicitis, and mixed with other causes of abdominal pain. ${ }^{12}$ When the relationship between a late diagnosis and an increased complication rate is considered, it is clear that some auxiliary techniques that that lead to an early diagnosis are needed. ${ }^{13}$

In terms of negative laparotomy, 30 of 200 patients $(15 \%)$ operated on in our series had no pathological findings consistent with acute appendicitis. This is also consistent with the negative laparotomy rate described in the literature. ${ }^{14,15}$

The Alvarado score is a scoring system that was developed to facilitate the diagnosis of acute appendicitis. In 2011, a compilation by Ohleda et $\mathrm{al}^{16}$ showed that when the predictive 
Table IV. Evaluations About the Alvarado Score.

\begin{tabular}{|c|c|c|c|c|}
\hline \multicolumn{5}{|c|}{ Alvarado score } \\
\hline \multirow{3}{*}{ USG } & & Mean \pm SD & MEDIAN & $\mathrm{P}$ \\
\hline & Positive: & $7.76 \pm 1.56$ & 8 & \multirow{2}{*}{0.001} \\
\hline & Negative & $6.45 \pm 1.71$ & 7 & \\
\hline \multirow[t]{2}{*}{ Histopathology } & Positive: & $7.83 \pm 1.38$ & 8 & \multirow{2}{*}{0.001} \\
\hline & Negative & $5.23 \pm 1.59$ & 5 & \\
\hline \multirow[t]{2}{*}{$\mathrm{WBC}\left(/ \mathrm{mm}^{3}\right)$} & $\geq 10.000$ & $7.89 \pm 1.50$ & 8 & \multirow{2}{*}{0.001} \\
\hline & $<10000$ & $5.84 \pm 1.35$ & 6 & \\
\hline \multirow[t]{2}{*}{ ANC $\left(/ \mathrm{mm}^{3}\right)$} & $\geq 7.500$ & $7.94 \pm 1.38$ & 8 & \multirow{2}{*}{0.001} \\
\hline & $<7.500$ & $5.85 \pm 1.62$ & 6 & \\
\hline \multirow[t]{2}{*}{ MPV(fL) } & $\geq 7.4$ & $7.38 \pm 1.61$ & 8 & \multirow{2}{*}{0.416} \\
\hline & $<7.4$ & $7.53 \pm 1.80$ & 8 & \\
\hline
\end{tabular}

USG: Ultrasonography; WBC: White blood count; ANC: Absolute neutrophil count; MPV: Mean platelet volume; SD: Standard deviation

value of the Alvarado score was taken as 5, the sensitivity was $99 \%$ and the specificity was $43 \%$; when predictive value was taken as 7 , the sensitivity was $82 \%$ and the specificity was $81 \%$. In a study conducted in 2007 , among patients that were 7 years old and over admitted to the emergency service with abdominal pain, appendicitis was detected in $3 \%$ of those that had a score of 3 or under, and in $36 \%$ of those that had a score between 4 and $6{ }^{17}$. In our study, the average Alvarado score of the patients with a diagnosis of acute appendicitis confirmed by histopathology was 7.83, while the patients that had negative pathology results with acute appendicitis had an average score of $5.23(\mathrm{p}=0.001)$.

Ultrasonography is the preferred imaging method in the diagnosis of acute appendicitis in children because it is non-invasive, inexpensive, easy to apply and accessible, and does not deliver a dose of radiation. ${ }^{18}$ In a systematic review conducted in 2007, USG sensitivity was reported as $83.7 \%$ and the specificity was $95.9 \%$ in the diagnosis of acute appendicitis. ${ }^{19}$ Similar results were obtained in a metaanalysis performed in children and adults in 2006.20 The sensitivity of USG in our study was calculated as $81.1 \%$, with a specificity of $56.6 \%$, a positive predictive value of $91.3 \%$, a negative predictive value of $34.6 \%$ and accuracy of $77.5 \%$. Thirty of 49 patients were negative according to USG, thought to be due to radiological difficulties or having appendicitis histologically. In appendicitis cases, particularly in the early term, histopathological findings are monitored in the focal area and it is difficult to detect these cases by imaging methods. The experience of the radiologist plays an important role in these cases. ${ }^{21}$

In the studies on the diagnosis of acute appendicitis, the sensitivity of WBC being $\geq 10,000 / \mathrm{mm}^{3}$ was $61-73 \%$, and the specificity has been reported as $59-72 \% 22,23$. We found that WBC sensitivity was $78.2 \%$ and the specificity was $23.3 \%$. In the literature, when ANSI $\geq 7500 / \mathrm{mm}^{3}$, the sensitivity was $71-89 \%$ and the specificity was $48-80 \% .{ }^{24,25}$ Similar to our study, the sensitivity was found to be $77.6 \%$, and the specificity was $33.3 \%$.

In a study by Albayrak et al. ${ }^{26}$, they found that the MPV level of patients diagnosed with acute appendicitis was lower than that in the healthy control group. Similarly, Tanrikulu et al. ${ }^{27}$ found lower MPV levels in patients with acute appendicitis. The best predictive value of MPV was 5, and the sensitivity, specificity, positive predictive value and negative predictive value were $45 \%, 89.2 \%, 87.3 \%$ and $49.6 \%$, respectively. In 2015, Erdem et al. ${ }^{28}$ reported that the MPV values of patients with a diagnosis of acute appendicitis were $7.4 \pm 0.9 \mathrm{fL}$ while the control group had 9.1 $\pm 1.6 \mathrm{fL}$; however, WBC and neutrophil percentage supported the diagnosis better than MPV. Narc1 et al. ${ }^{29}$, on the contrary, said they had found MPV values of $7.92 \pm 1.68 \mathrm{fl}$ in patients with acute appendicitis and $7.44 \pm 1.34 \mathrm{fl}$ in the healthy 
control group. They also found that the CRP, WBC and MPV values were significantly higher in the patient group $(\mathrm{p}<0.001)$. We also did not observe a difference between groups in terms of the MPV value in our study. There was no significant difference in WBC, ANSI or CRP levels $(\mathrm{p}<0.05)$. But, our control group did not include healthy patients, as this group contained patients that presented with abdominal pain, received a preliminary diagnosis of acute appendicitis, were operated on and had a negative result for acute appendicitis by histopathology. We think that the difference in the results is due to that fact.

According to our study the use of Alvarado Scoring System with USG is more effective and accurative than USG performing alone. May be the diagnostic cut off value of Alvarado Score reduce to 5 from 7 .

We recommend performing USG on each patient with right lower quadrant pain and suspected appendicitis admitted to the emergency department, and to operate on patients with a USG-supported appendicitis diagnosis and an Alvarado score of 7 and above. Patients with a diagnosis of appendicitis not supported by USG and with an Alvarado score lower than 7 should be closely monitored.

\section{REFERENCES}

1. Ergul E. Importance of family history and genetics for the prediction of acute appendicitis. Internet J Surg 2007; 10: 2 .

2. Nance ML, Adamson WT, Hedrick HL. Appendicitis in the young child: a continuing diagnostic challenge. Pediatr Emerg Care 2000; 16: 160-162

3. Richard G. Bachur, Kara Hennelly, Michael J. Diagnostic imaging and negative appendectomy rates in children: effects of age and gender. Pediatrics 2012; 129: 5

4. Paajanen $\mathrm{H}$, Mansikka A, Laato M, Ristamäki R, Pulkki $\mathrm{K}$, Kostiainen S. Novel serum inflammatory markers in acute appendicitis. Scand J Clin Lab Invest 2002; 62: $579-584$.

5. Madan S. Pediatric appendicitis score. Journal of Pediatric Surg 2002; 37: 877-881.

6. Goldman RD, Carter S, Stephens D, Antoon R, Mounstephen W, Langer JC. Prospective Validation of the Pediatric Appendicitis Score. J Pediatr 2008; 153: 278-282

7. Erkasap S, Ates E, Ustuner Z, Sahin A, Yllmaz S, Yasar B. Diagnostic value of interleukin- 6 and C-reaktive protein in acute appendicitis. Swiss Surg 2000; 6: 169-172.
8. Ilkhanizadeh B, Owji AA, Tavangar SM, Vasei M, Tabei SM. Spot urine 5-hydroxy indole acetic acid and acute appendicitis. Hepatogastroenterology 2001; 48: 609-613.

9. Pipal DK, Kothari S, Shrivastava H, Soni A, Pipal V. To evaluate the diagnostic accuracy of alvarado score, C-reactive protein, ultrasonography and computed tomography in acute appendicitis and to correlate them with operative and histological findings. Int Surg J 2017; 4: 361-367

10. Alvarado AA. Practical score for early diagnosis of acute appendicitis. Ann Emerg Med 1986; 15: 557-564.

11. Almaramhy HH. Acute appendicitis in young children less than 5 years: review article. Ital J Pediatr 2017; 43: 15

12. Becker T, Kharbanda A, Bachur R. Atypical clinical features of pediatric appendicitis. Acad Emerg Med Off J Soc Acad Emerg Med 2007; 14: 124-129.

13. Omundsen M, Dennett E. Delay to appendicectomy and associated morbidity: a retrospective review. ANZ J Surg 2006; 76: 153-155

14. Bergeron E. Clinical judgement remains of great value in the diagnosis of acute appendicitis. J Can Chir 2006; 49: 96-100.

15. Anderson RE, Hugander A, Thulin AJ. Diagnostic accuracy and perforation rate in appendicitis: Association with age and sex of the patient and with appendectomy rate. Eur J Surg 1992; 158: 37-41.

16. Ohle R, O'Reilly F, O’Brien KK, Fahey T, Dimitrov BD. The Alvarado score for predicting acute apandicitis: a systematic review. BMC medicine 2011; 9: 139.

17. McKay R, Shepherd J. The use of the clinical scoring system by Alvarado in the decision to perform computed tomography for acute appendicitis in the ED. Am J Emerg Med 2007; 25: 489-493.

18. Mostbeck G, Adam EJ, Nielsen MB, et al. How to diagnose acute appendicitis: ultrasound first. Insights Imaging. 2016; 7: 255-263.

19. Al-Khayal KA, Al-Omran MA. Computed tomography and ultrasonography in the diagnosis of equivocal acute appendicites. A meta-analysis. Saudi Med J 2007; 28: 173-180.

20. Doria AS, Moineddin R, Kellenberger CJ, et al. US or CT for Diagnosis of Appendicitis in Children and Adults? A Meta-Analysis. Radiology 2006; 241: 83-94.

21. Rosai J. Rosai and Ackerman's surgical pathology. (9th ed). Gastrointestinal tract-appendix. Newyork: Elsevier, 2004: 757-758.

22. Kafetzis DA, Velissariou IM, Nikolaides P, et al. Procalcitonon as a predictor of severe appendicitis in children. Eur J Clin Microbiol 2005; 24: 484-487.

23. Wu JY, Chen HC, Lee SH, Chan RC, Lee CC, Chang SS. Diagnostic role of procalcitonin in patients with suspected appendicitis. World J Surg 2012; 11: 17441749.

24. Al-Gaithy ZK. Clinical value of total blood cells and neutrophil counts in patients with suspected appendicitis: retrospective study. WJES 2012; 7: 32. 
25. Yang HR, Wang YC, Chung PK, et al. Role of leukocyte count, neutrophil percentage, and C-reactive protein in the diagnosis of acute appendicitis in the elderly. Am Surg 2005; 71: 344-347.

26. Albayrak Y, Albayrak A, Albayrak F, et al. Mean platelet volume: a new predictor in confirming acute appendicitis diagnosis. Clin Appl Thromb Hemost 2011; 17: 362-366.

27. Tanrıkulu CS, Tanrıkulu Y, Sabuncuoğlu MZ, Karamercan MA, Akkapulu N, Coşkun F. Mean platelet volume and red cell distribution width as a diagnostic marker in acute appendicitis. Iran Red Crescent Med J 2014; 16: e10211.
28. Erdem H, Aktimur R, Cetinkunar S, et al. Evaluation of mean platelet volume as a diagnostic biomarker in acute appendicitis. Int Clin Exp Med 2015; 15: 12911295.

29. Narcı H, Turk E, Karagülle E, Togan T, Karabulut K. The role of mean platelet volume in the diagnosis of acute appendicitis: a retrospective case-controlled study. Iran Red Crescent Med J 2013; 15: e11934. 